\title{
DISEÑO Y CREACION DE UN MATERIAL EDUCATIVO COMPUTARIZADO (YAKU 1.0) REFERENTE A LA TEMATICA DEL AGUA Y SU GESTIÓN INTEGRAL
}

\section{DESIGN AND CREATION OF A EDUCATIONAL COMPUTER MATERIAL (YAKU 1.0) RELATING TO THE THEME OF THE WATER AND INTEGRATED MANAGEMENT}

\author{
César Augusto Bustamante Toro ${ }^{1}$ y Héctor Fabio Álzate Ríos ${ }^{1}$. \\ ${ }^{1}$ Profesores programa de Licenciatura en Biología y Educación Ambiental, Facultad de Educación, Universidad del Quindío. \\ Fecha de recibido: Febrero 3 de 2010 \\ Fecha de aceptado: Junio 9 de 2010 \\ Correspondencia: Programa de Licenciatura en Biología y Educación Ambiental Universidad del Quindío. Av. Bolívar calle 12 norte Armenia Quindío. Correo \\ electrónico: ceabusta@uniquindio.edu.co
}

\section{RESUMEN}

Mediante esta investigación se logró crear y diseñar un material educativo computarizado (MEC) denominado YAKU versión 1.0, con el objeto de promover en los usuarios de diferentes comunidades educativas, espacios de reflexión, análisis y discusión con respecto a la conservación y uso eficiente del agua. YAKU 1.0 es un material didáctico multimedia en formato CD ROM, sobre la temática del agua y su gestión integral para la vida y el desarrollo sostenible; para ello se utilizaron las ventajas multimediales (texto, imágenes, animaciones y sonido) y empleo de Herramientas de desarrollo multimedia como: Neobook 5.5 como utilitario principal, Windows Movie Maker 5.1, Flash MX, editores fotográficos, entre otros.

Asimismo, en dicha investigación se logró desarrollar una metodología propia y dinámica, siendo consecuentes con el contexto socio-educativo y cultural. Se aplicaron los principales parámetros considerados para la creación y diseño de MECs teniendo en cuenta dos fases: Fase 1: Prediseño y condiciones pedagógicas del MEC, Fase 2: Procesamiento y condiciones técnicas del MEC. Todo lo anterior, con el propósito de generar un campo de acción que permita la conformación de grupos de desarrollo de MECs en diferentes áreas del conocimiento; igualmente, se pretende promover el uso del computador y las TIC como herramienta pedagógica fundamental en la interacción del conocimiento en el sector agua.

Palabras Clave: Material educativo computarizado (MEC), YAKU, material didáctico, cátedra del agua, herramienta multimedia, gestión integral del agua.

\begin{abstract}
Through this research we were able to create and design an educational computer material (ECM) named YAKU 1.0, in order to promote in the users of different educational communities, opportunities for reflection, analysis and discussion regarding the conservation and efficient use of water. YAKU 1.0 is a multimedia learning material on CD ROM, about the water and water management in an integrated way for life and sustainable development, therefore it was used multimedia (text, images, animations and sound) and development tools like Neobook 5.5 as the main utility, Windows Movie Maker 5.1, Flash MX, photo editors, among others. Also, in this research it was possible to develop a unique and dynamic methodology, attached to the socio-educational and cultural context. We applied the main parameters considered for the creation and design of ECM taking into account two phases: Phase 1: Pre-design and learning conditions of the ECM, Phase 2: Processing and technical conditions of the ECM. All the above, in order to generate a field of action allowing the formation of ECM development groups in different areas of knowledge, likewise the research aims to promote the use of computers and TIC as an important learning tool in the interaction of knowledge in the water topic.
\end{abstract}

Key words: educational computer material, YAKU, classroom, material didactic, tool, multimedia, water integral management.

\section{INTRODUCCIÓN}

Los Materiales Educativos Computarizados (MEC) son una herramienta multimedia con gran énfasis en lo gráfico y cuenta habitualmente con una agradable interfaz, para así atraer la atención inmediata del usuario y con elementos lúdicos y estéticos como imágenes de muy buena definición y excelente manejo del color, fotografías o segmentos de video cuyo movimiento es comparable a la televisión, sonido estéreo sin restricciones de timbre o tono, y en algunos casos con la misma calidad de un disco compacto (García-Duque); los MEC también son entendidos como las diferentes aplicaciones informáticas cuyo objetivo es apoyar el aprendizaje y, están adquiriendo cada vez más jerarquía en los procesos de enseñanza-aprendizaje asistido por computador, para favorecer la motivación y la curiosidad intelectual de los estudiantes. De lo anterior, se desprende la necesidad de involucrar el computador como una herramienta y recurso didáctico moderno de la educación aplicada a las diferentes áreas del conocimiento. 
Para llevar a cabo dicha necesidad se parte de la pregunta ¿Cómo realizar un MEC, para facilitar la enseñanza y comprensión de la temática del agua y su gestión integral para la vida y el desarrollo sostenible? para este caso, promover el trabajo interdisciplinariedad en las instituciones de educación superior, a través de los programas académicos en una temática común "el agua" que suscita múltiples realidades e intereses. Igualmente, construir conocimiento y fortalecer las interacciones de la comunidad académica con los procesos de docencia, investigación y proyección social.

Para darle respuesta a este interrogante, se formuló el siguiente objetivo: diseñar y crear un material educativo computarizado como herramienta didáctica e interactiva, donde se ponga en práctica los conceptos de programación orientados a objetos y software para crear aplicaciones multimedia.

Para contextualizar sobre el diseño y creación de MEC se tomo como fuente teórica lo concerniente a: Teorías sobre el diseño de Materiales educativos computarizados, Teorías de Aprendizaje y Metodologías de desarrollo de materiales educativos computarizados. Estas teorías y metodologías permitieron enfocar una visión más amplia de la forma en que se genera un MEC.

Con base a esta premisa, se puede llegar al ajuste de una metodología original didáctica y dinámica teniendo en cuenta el contexto educativo y socio-cultural, con el fin de aplicar los principales parámetros considerados para el desarrollo del MEC.

\section{La Hidroinformática y la Gestión Integral del Agua}

Para mejorar las problemáticas asociadas al agua se ha promovido una estrategia holística, conocida como la gestión integral de los recursos hídricos (GIRH) que busca asegurar un uso óptimo y sostenible del agua para el desarrollo económico y social, mientras se protege y mejora el valor ecológico del ambiente (Visscher et al., 1999; GWP, 2000). La GIRH es necesaria para combatir, el incremento de la escasez de agua y la contaminación. Se puede emplear un gran número de estrategias, métodos y técnicas, incluyendo la conservación del agua, la reutilización y el manejo de las aguas residuales. Además, se requiere crear un marco legal e institucional que permita la aplicación de estos principios, acompañado de herramientas de trabajo y metodologías para su implementación (Sánchez y Sánchez, 2004).

Uno de los problemas más significativos que tiene la puesta en práctica de saberes y conceptos para la GIRH es la aprehensión y la apropiación social del conocimiento a todo nivel. En ese aspecto los diferentes actores no reciben productos de información orientados a sus características sociales, políticas, económicas, culturales y ambientales específicas que les permitan aplicar los conocimientos en su entorno.

Las investigaciones han comprobado que no es suficiente con la generación de conocimiento para solucionar los conflictos y problemas asociados al recurso agua; pero es indispensable que la sociedad se apropie del conocimiento y lo apliquen a su quehacer cotidiano. No obstante, se debe reconocer que existen obstáculos que influyen en la apropiación de la temática del agua como son: barreras culturales al cambio, producción de información y conocimiento que no corresponde a las audiencias que se intentan alcanzar, insuficientes e ineficientes productos de información y comunicación sobre la gestión de los recursos hídricos (AGUA, 2003).

En ese sentido, la formación mediada por el uso de las tecnologías de la información y la comunicación (TIC) pueden despertar el deseo de aprender, ya que los estudiantes pueden ser centro y protagonistas de su proceso de aprendizaje a través de las particularidades que ofrecen los entornos infovirtuales: la asincronía, la visión holística del aprendizaje, la flexibilidad, la planificación y organización, el trabajo interdisciplinario, el aprendizaje colaborativo, la comunicación entre los participantes y la gestión de la diversidad cultural sin olvidar la importancia del contexto en el aprendizaje (Bautista et al., 2006).

La hidroinformática se relaciona con el uso de modelos de simulación y las TIC para apoyar procesos académicos, científicos y socio-culturales que motiven y faciliten de manera democrática la participación de los diferentes actores e instituciones involucrados en la búsqueda de soluciones a los problemas asociados a la GIRH, con el propósito de garantizar la sostenibilidad del agua a las futuras generaciones.

Con base en las anteriores premisas, se logró diseñar y crear un material educativo computarizado (denominado YAKU 1.0), para dejar a disposición de diferentes usuarios de comunidades educativas e instituciones asociadas al sector GIRH. Este es un material didáctico multimedia en formato CD ROM, el cual permite la conformación de grupos de desarrollo de MEC para la producción de nuevas versiones que contribuyan a la temática del agua desde una visión sistémica e interdisciplinaria. Los nuevos diseños y creaciones de MEC, tienen como objetivos promover el uso del computador como herramienta pedagógica en las diferentes áreas del conocimiento.

\section{METODOLOGÍA}

El trabajo se desarrolló con base en la literatura general sobre temas relacionados a la parte técnico-científica del agua y la gestión integral del recurso hídrico y afines; por lo tanto esta información se empleó para el desarrollo del argumento o guión para luego diseñar y crear la herramienta computacional didáctica.

Para el diseño y creación del material educativo computarizado (MEC) denominado YAKU 1.0, se realizó una revisión bibliográfica sobre diferentes metodologías aplicadas a los MEC (autores) hasta llegar a la implementación de una metodología propia y dinámica, acordes con las necesidades del contexto socio-cultural y educativo, el cual se dividió en dos fases: 
Fase 1: Prediseño y condiciones pedagógicas del MEC Fase 2: Procesamiento y condiciones técnicas del MEC

En las Figuras 1 y 2 respectivamente, se aprecian los principales lineamientos considerados para el desarrollo metodológico del MEC.

Para la generación del MEC se utilizaron diferentes herramientas de desarrollo multimedia como: Neobook 5.5 como utilitario principal, Windows Movie Maker 5.1, Flash $M X$, editores fotográficos y de texto gif como Ulead COOL 3D 3.5, Reflet versión 2.5, editores de sonido digital como Cool Edit, editores de iconos como Easy Icons, generadores de Setup como Inno Setup 5.

\section{Primera fase MEC}

En la primera fase se identificó la necesidad de desarrollar MEC sobre la temática del agua (Figura 1), para ello se utilizaron fuentes primarias las cuales sirvieron para obtener información directa de la población como: Observación y entrevistas (anexos 1 y 2). Para la entrevista se utilizó las preguntas semiabierta y abierta, logrando conocer las actitudes, las opiniones y las experiencias de los participantes.

La entrevista se aplicó a veinte (20) participantes conocedores del tema sobre las TIC, ya que aportaron experiencias vividas, ideas en programación visual, utilización de herramientas informáticas, fuentes de consulta, entre muchas otras contribuciones.

Las encuestas y entrevistas aplicadas a algunos miembros de la comunidad educativa Uniquindiana evidenciaron la problemática (carencia de metodologías alternas a las tradicionales frente al tema del agua). Por lo tanto, surge la necesidad de desarrollar el MEC como alternativa didáctica que responda de manera lúdica y práctica, se formularon los objetivos propios del MEC y se seleccionó el tema o argumento de acuerdo a los objetivos buscados y con una relación frente al componente pedagógico que permitió definir el desarrollo de la temática frente a su perspectiva dinámica y las condiciones de los usuarios que va desde los estudiantes y docentes directamente relacionados con el tema del agua. Como ya se definió el tema o argumento, surge la necesidad de realizar consultas y recopilación de material (fotografías, videos, texto, gráficos, tablas, sonidos, entre otros) para ejecutar la redacción y diseño del guión, teniendo en cuenta que la información debe ser procesada por medio de herramientas de desarrollo multimedia antes mencionadas y de ésta forma adecuar los formatos al programa multimedia, para así generar el prediseño del MEC también denominado como la primera versión funcional.

Es de resaltar que en el desarrollo de la primera fase y al concluirla, se realizaron evaluaciones internas a través de encuestas (Anexo 3 y 4) aplicada a estudiantes de la Universidad del Quindío, con el fin de corregir posibles fallas y poder afrontar la fase dos.

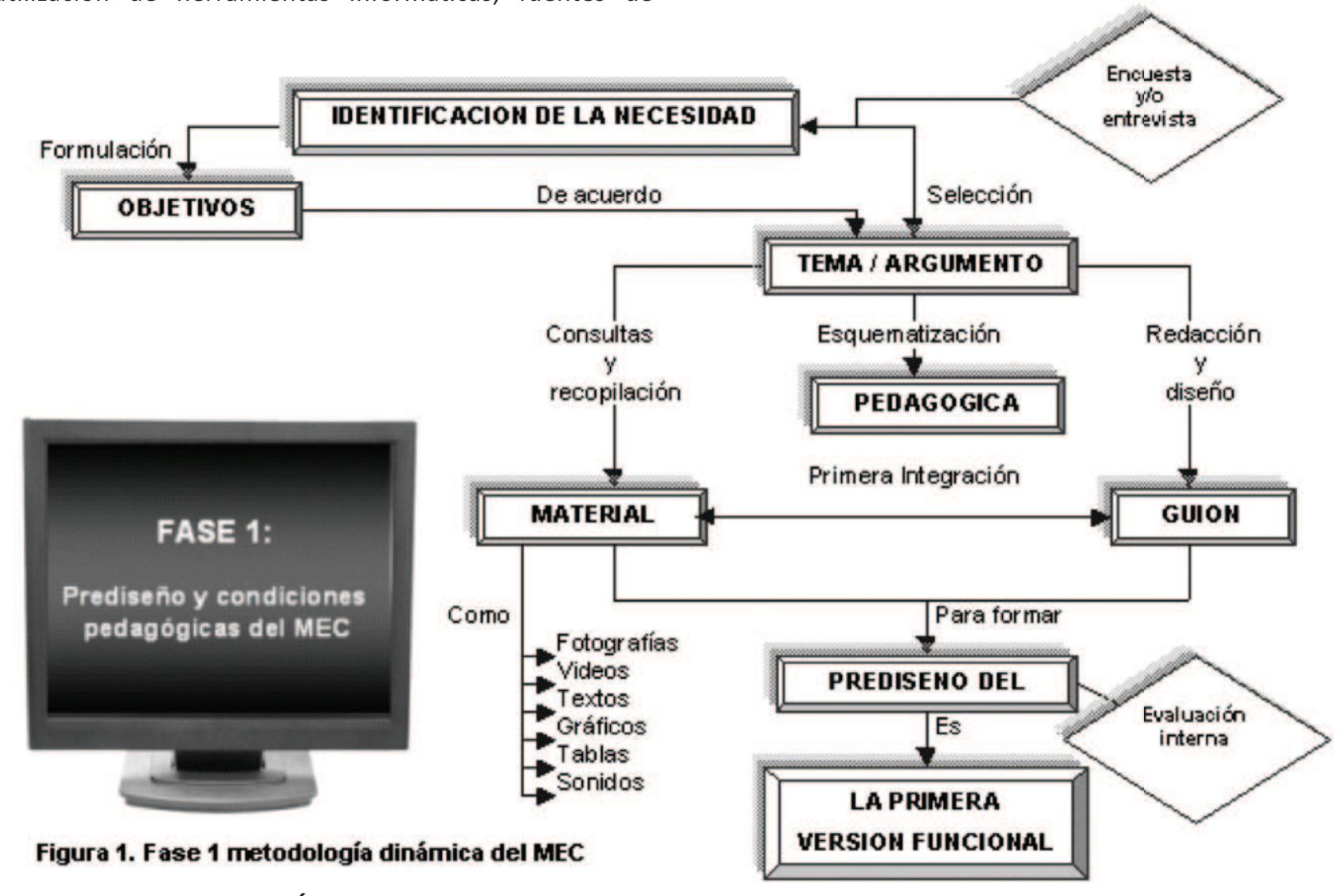

Tomado de: Álzate et al. (2008). 


\section{Segunda fase MEC}

En la segunda fase como punto de partida se utilizó el prediseño de la fase inicial, se desarrollo un procesamiento que consiste en la edición y adecuación del guión y del diseño de interfaz, lo que permitió organizar la información a través del armado y las constantes correcciones referente a la distribución de espacios en pantalla, colores, iconos de navegación, mensajes de texto y sonidos acordes. Los hipervínculos en esta etapa deben ser adecuados al orden de la información que se ha determinado en el guión, de esta forma se buscan las capacidades de interactividad con el usuario, teniendo en cuenta que la estética gráfica debe ser acorde al usuario final.

Después de sucesivas correcciones (Figura 2), se puede apreciar que la zona de armado es cíclica, lo que indica que la cantidad de correcciones es variable. El resultado de ésta etapa debe llevar a la puesta en marcha del MEC para la realización de pruebas que permitieron realizar la evaluación externa con la ayuda de usuarios reales (posibles destinatarios del MEC, estudiantes de los programas académicos de Licenciatura en Biología y Educación Ambiental e Ingeniería Civil y el Diplomado en Tratamiento y Reciclaje de Aguas Residuales de la Facultad de Ingeniería Universidad del Quindío); encontrándose algunas fallas propios de la temática y del sistema entre otros; además de las pruebas en las condiciones técnicas referente a su instalación y su estabilidad con el sistema operativo y hardware. Finalmente se logró el diseño y creación de la versión 1.0 del MEC (YAKU) que continúa en una etapa de mantenimiento, donde es probable encontrar aspectos no contemplados a la largo de las fases y que motivan a las posteriores actualizaciones del MEC con la ayuda permanente de los usuarios.

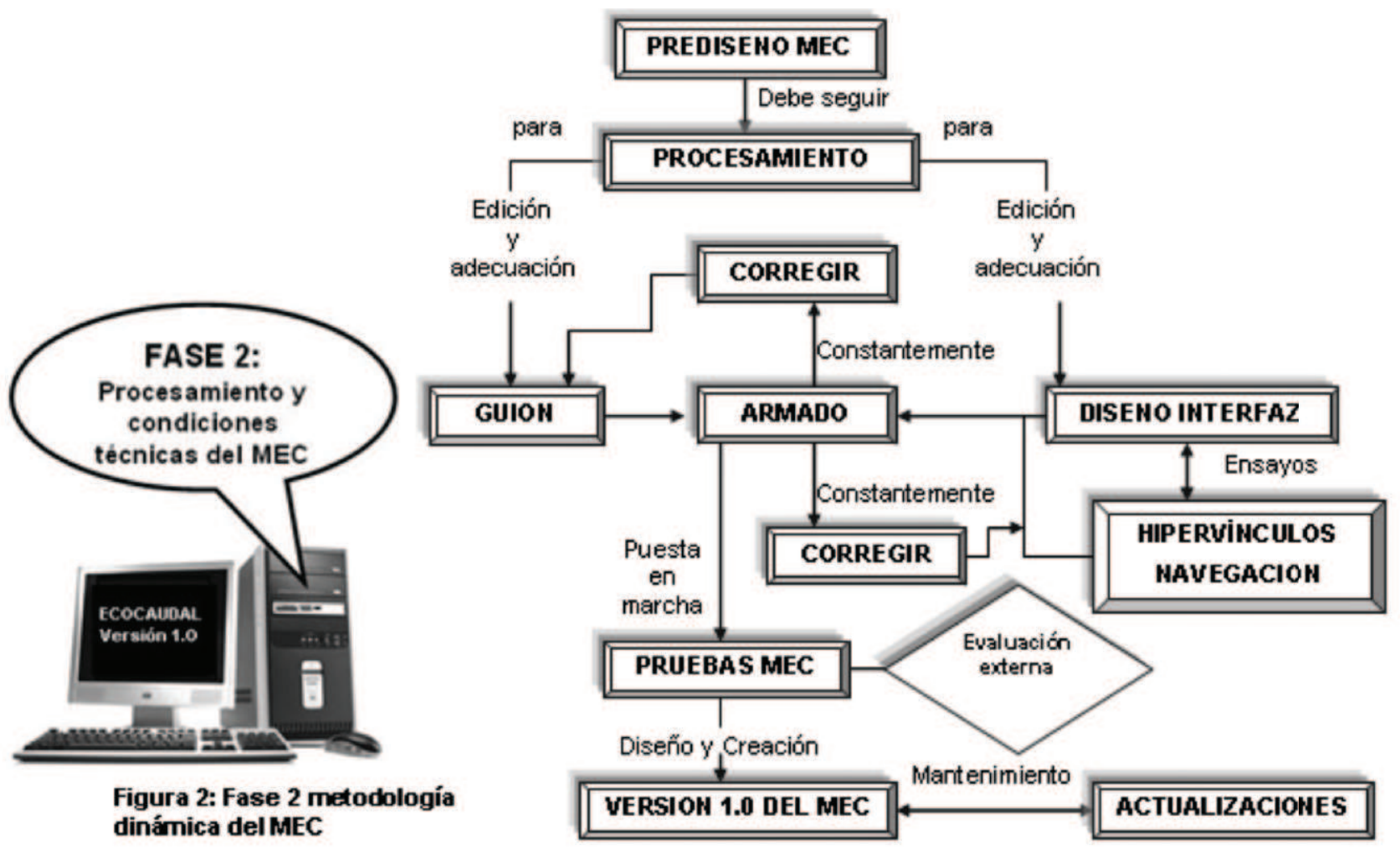

Tomado de: Álzate et al. (2008).

\section{RESULTADOSY ANALISIS}

\section{FASE 1: PREDISEÑO Y CONDICIONES PEDAGÓGICAS DEL} MEC

En la primera fase se logró realizar cada uno de los siguientes pasos:

a. Identificar la necesidad.

b. Formular los objetivos. c. Selección del tema o argumento.

d. Componente pedagógico.

e. Recopilación de material.

f. Redacción y diseño del guión.

g. Prediseño del MEC.

h. Primera versión funcional del material educativo computarizado.

A continuación se detalla los logros obtenidos en los pasos más significativos: 


\section{Identificación de la necesidad}

Se utilizaron fuentes primarias las cuales sirvieron para obtener información directa de la población como: encuestas y entrevistas.

A manera de síntesis todo lo anterior arroja como respuesta el siguiente listado:

- Carencia de materiales y medios didácticos claros para la comprensión de temas y subtemas actuales en la temática de los recursos hídricos y su manejo integral.

- Falta de utilización de la sala de informática de una manera difundida para todas las áreas, lo que conduce a un desaprovechamiento de la tecnología disponible.

- Falta de MECs específicos para una temática determinada (especializada y contextualizada).

Los análisis de las entrevistas y encuestas aplicadas, tuvo como base consultas a conocedores de temas: educativos, informáticos, limnológicos, hidrológicos, hidráulicos, calidad y gestión del agua. Estos presentaron puntos de vista positivos y motivacionales frente al cuestionamiento sobre crear un MEC. Por otra parte, se encontraron indicadores sobre la necesidad de implementar el MEC en las diferentes instituciones educativas, la mayoría opinó que debe hacerse en diferentes niveles desde el Bachillerato hasta el nivel Universitario. Las entrevistas fueron percibidas como significativas, ya que los entrevistados manifiestan el propósito y la necesidad de implementar el desarrollo de MECs debido a su pertinencia. Además, expresaron conocer experiencias con MEC aplicado al aprendizaje de la informática y así resaltaron la importancia de involucrar la temática de los recursos hídricos y en especial su gestión integral y sostenibilidad, puesto que es poco lo conocido y mucho lo que se debe hacer para conservar un recurso fundamental para la vida.

Las entrevistas, las observaciones y la revisión y recopilación de información produjeron las siguientes necesidades:

- Diseñar y Crear un MEC en formato CD ROM aplicando los conceptos de programación orientada a objetos, para crear aplicaciones multimedia.

- Realizar el MEC en formato CD ROM multimedia sobre la temática del agua.

\section{Formulación de los objetivos del MEC}

Los siguientes son los objetivos propuestos para el MEC:

Generar conocimiento en el desarrollo de herramientas infovirtuales.

- Motivar a los usuarios del MEC en la gestión de recursos hídricos y las prácticas de ahorro y uso eficiente del agua.
- Aportar elementos para la construcción de una cultura social que mejore los hábitos, la visión del consumo y la conservación del recurso hídrico.

- Promover ideas e iniciativas con relación al acceso, uso y aprovechamiento del agua de manera racional, segura y equitativa.

- Permitir la práctica y la adquisición de habilidades por parte de la autoridad ambiental sobre los conceptos básicos en la gestión integral del agua.

- Producir bases conceptuales, teóricas y prácticas que fortalecerán lo multi e interdisciplinario entre las líneas de investigación en: Calidad del agua en corrientes hídricas y de Biología y Educación ambiental de la Universidad del Quindío.

Recopilación de material, redacción y diseño del guión para el prediseño del MEC

Cada una de las unidades permitió redactar el guión para recopilar los materiales necesarios que generaron las animaciones, la decoración estética y la motivación, para que el usuario enfrentara la interfaz y de ésta forma convertir los materiales recolectados (fotografías, videos, texto, gráficos, tablas, sonidos, entre otros) con herramientas de desarrollo multimedia como: Neobook 5.5, Windows Movie Maker 5.1, Flash MX, editores fotográficos y de texto gif como Ulead COOL 3D 3.5, editores de sonido digital como Cool Edit, editores de iconos como Easy Icons, generadores de Setup como Inno Setup 5 entre otros, haciendo especial énfasis a la base del MEC que fue en Neobook Profesional 5.5 para Windows 95/98/2000/XP, debido a que se caracteriza como una herramienta de autor multimedia para crear y publicar diferentes tipos de MEC multimedia interactivo, usando cuadros, gráficos, cajas de texto, botones de comando, globos y cintas para su almacenamiento vía CD-Rom y que permitió el control de las pantallas y otros elementos de la publicación electrónica, su organización y luego la compilación dentro de los archivos punto EXE (.exe) autosoportados y así lograr generar el prediseño del MEC denominado YAKU 1.0.

\section{Teorías de aprendizaje que sustenta el MEC}

EI MEC YAKU 1.0, sigue determinados planteamientos conductistas, tales como desglosar la información tratada en objetivos y unidades, modelo típico de enseñanza programada y ramificada que contiene así mismo algunas actividades que pretenden dar respuesta del usuario y ciertos refuerzos en las actividades complementarias. De todo esto resulta en YAKU la necesidad de presentar la información partiendo del diagnóstico para explorar los conocimientos previos del estudiante, e imágenes que pueden ser conocidas por los usuarios, basándose en el paradigma constructivista, donde el usuario construye y recrea (volver a crear) porque contempla sistemas 
hipertexto, en los cuales se organiza la información de manera no lineal, cada usuario puede recorrer, navegar o utilizar personal y creativamente la información. Esto se forja con los fotogramas, el video, el contenido de las unidades y el glosario (hipervínculo por globos o cintas) que se muestran en el MEC.

De esta forma, YAKU $\mathbf{1 . 0}$ podría mejorar el proceso de aprendizaje a través del computador como recurso instruccional, razón por la cual se muestra una interfaz en la que se da la combinación de sonidos, colores, imágenes, videos, así como otros elementos que ayudan al diseño de las pantallas. Estos elementos ofrecerán a los estudiantes un ambiente favorable para la construcción de aprendizajes significativos, además de permitir diferentes grados de interactividad. Este MEC ofrece opciones al estudiante como: Selección múltiple con múltiple respuesta y única respuesta, falso o verdadero, actividades lúdicas como: Sopa de letras, rompecabezas de habilidad memorística y actividades de texto caracterizadas por una retroalimentación inmediata debido a que el estudiante verifica el resultado de las respuestas en el acto. A esto se añade una retroalimentación a largo plazo con actividades de autoevaluación por medio de preguntas abiertas que se pueden guardar en carpetas por nombre del estudiante en formato.txt (almacenamiento de la información) que sirven para promover el debate sobre la temática del agua, o aportes sobre el diseño, funcionamiento, mantenimiento y actualizaciones del MEC.

Con la metodología dinámica de diseño de YAKU 1.0, también se puede desarrollar la creatividad, por tanto el estudiante puede navegar libremente, esto facilitará la posibilidad que se logre aprendizajes significativos no memorísticos, y para ello los nuevos conocimientos deben relacionarse con los saberes previos que posea el aprendiz (Ausubel, et al., 1997). Evidenciado en las actividades de reflexión y lecturas que aportan una interesante visión sobre los contenidos y, en actividades de aplicación como crear un filtro casero para tratar el agua de consumo doméstico.

EI MEC YAKU 1.0 con las características arriba señaladas, será más o menos eficiente según la calidad y flexibilidad de las respuestas que pueda ofrecer el profesor que lo apliqué. En este sentido, más que buscar la inteligencia en el profesor lo que se desea es contribuir al desarrollo de la inteligencia y habilidad mental del estudiante. Más aún la perspectiva constructivista está presente en YAKU, no sólo por las facilidades suministradas por el sistema para que el estudiante efectúe actividades, sino también porque su diseño es conforme con la idea de que el estudiante construya su conocimiento a través de la interiorización de actividades y la organización de operaciones en estructuras flexibles, esto es, en estructuras metacognitivas.

Se debe recordar que los MECs son sólo una herramienta educativa (transmiten información, son motivacionales, ofrecen otras formas de trabajo y construcción del conocimiento, entre otras.), pero no son sustitutos del profesor, jamás podrán serlo, tomando en consideración una de las cuestiones más sobresalientes en desarrollo del ser humano: El aspecto afectivo, que no lo proporcionan los medios tecnológicos por sí mismos, función que cumple sobradamente la figura del maestro. Es él quien acompañará al alumno en el proceso de organizar la realidad y la información que lo rodea, para que pueda hacer un uso productivo de estas tecnologías y construir su propio conocimiento. Es el profesor el que tendrá que hacer uso adecuado del mismo para mejorar los procesos de aprendizaje en su entorno educativo, creando ambientes de aprendizajes significativos (De La Mora Sánchez, 2002).

Al igual que en la enseñanza presencial, es necesario para crear y diseñar un MEC tener en cuenta las características cognitivas del estudiante, su motivación, sus conocimientos previos y el contexto social. Por esta razón también se crearon algunas recomendaciones y guía de uso para profesores y estudiantes.

\section{Evaluaciones internas y externas}

Al finalizar la primera fase del MEC se realizaron varias evaluaciones internas, con estudiantes y docentes de la Universidad del Quindío para corregir posibles fallas y poder afrontar la fase dos, los principales resultados se resumen en los siguientes comentarios:

- El color puede ser más llamativo. Sería bueno un ítem de recomendaciones de conservación del agua y protección.

- Le falta un diseño un poquito novedoso. De pronto cambiar el tipo de letra y contraste de colores y añadir animaciones para las fotografías.

- Como sugerencia, usar colores un poco más subidos de tono, no usar grises o claros y agregar sonidos a los botones de navegación.

- Se debe cambiar el orden de algunos subtemas para que sean más acordes con el conocimiento inicial del estudiante.

- Las anteriores sugerencias se tuvieron en cuenta para modificarlas en el guión, diseño y funcionamiento del MEC.

\section{FASE 2: PROCESAMIENTO Y CONDICIONES TÉCNICAS DEL MEC}

Finalmente se logró el diseño y creación de la versión 1.0 del MEC (YAKU) que continúa en actualización constante y permanente. Para resumir las interpretaciones de los resultados de las evaluaciones internas y externas, se realizó la tabla 1, la cual se titula catalogación y valoración multimedia aplicada a YAKU $\mathbf{1 . 0}$ donde se esquematizó un sumario de las principales características de este MEC 
Título de I material: YAKU 1.0

Autor: HÉCTOR FABIO ALZATE RÍOS

Autor: CESAR AUGUSTO BUSTAMANTE TORO
Idioma: ESPAÑOL

E-mail: hfalzate@uniquindio.edu.co

Página Web:

http://www.uniquindio.edu.co/uniquindio/facultades/educacion/Lic_Biologia/cinaed/profe/ecocaudal.html

Temática: Cátedra del agua

Objetivos:

\ Motivar a los usuarios del MEC en la gestión de recursos hídricos.

\ Promover ideas e iniciativas con relación al acceso, uso y aprovechamiento del agua de manera segura y equitativa.

Contenidos qu e se tratan : La siguiente lista forma parte de los temas y subtemas que fluyen en el sistema para permitirle al usuario el entendimiento de la temática tratada.

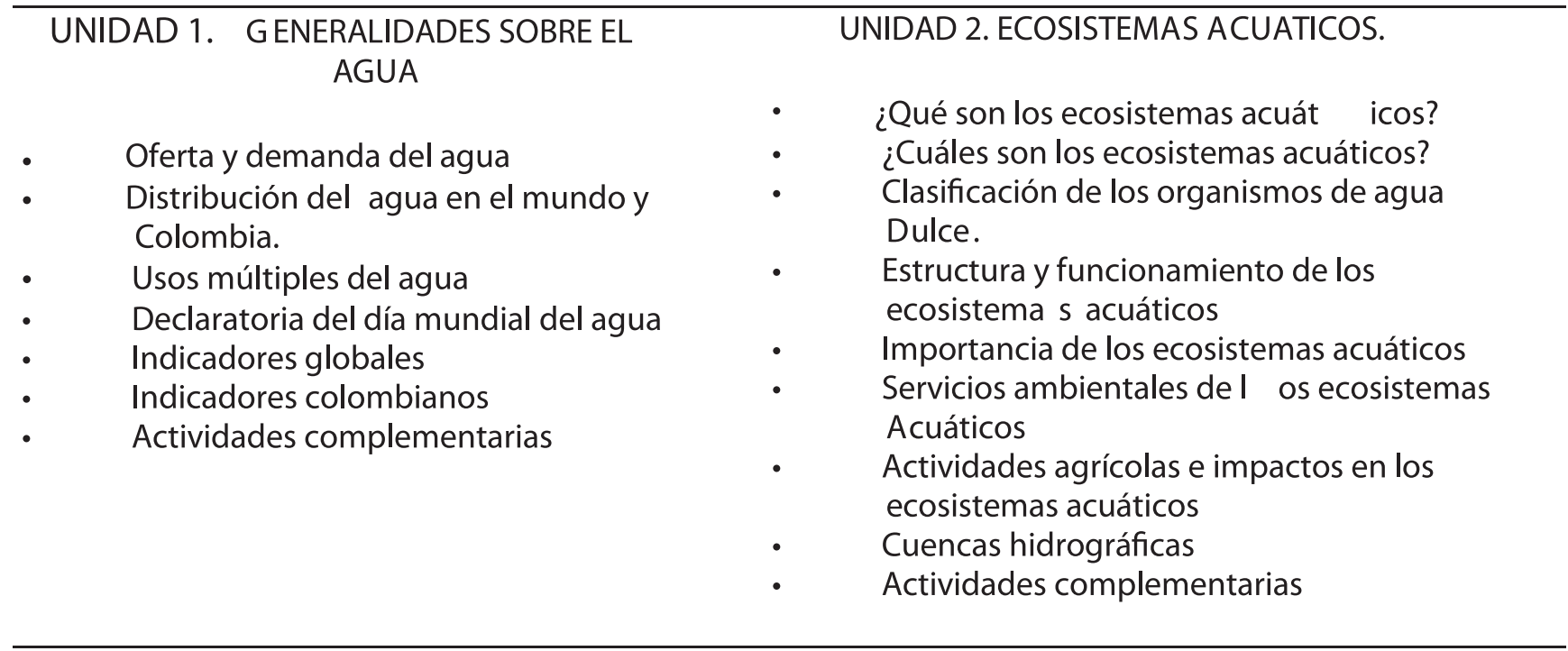




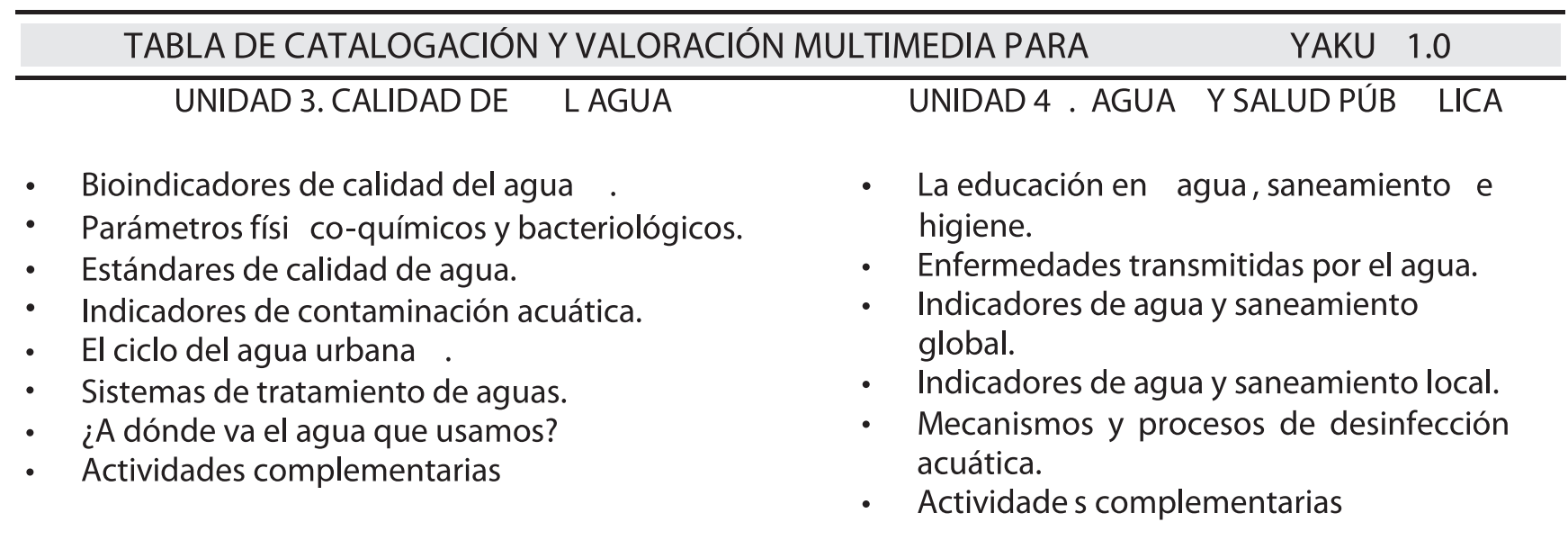

UNIDAD 5 AGUA, CULTURAY EDUCACION

- La educación en el manejo integral del recurso hídrico

- ¿Qué es el manejo integral del recurso Hídrico?

- Principios de Dublin .

- Perspectivas para la gestión integral del recurso hídrico .

- Agua y género.

- Actividades complementarias

\section{UNIDAD 6. RECOMENDACIONES PARA EL AHORROY USO EFICIENTE DEL AGUA}

- Recomendaciones para conservar el agua dentro de casa .

- Recomendaciones para conservar el agua fuera de casa .

- ¿Qué ventajas trae a un país el uso racional de agua?

- Actividades para mejorar el agua en su Comunidad.

- Actividades complementarias .

DESTINATARIOS: Va dirigido a todas las personas interesadas en el manejo y cuidado del agua, a profeso res sin importar su asignatura y estudiantes universitarios.

TIPOLOGÍA: Actividades interactivas - unidad didáctica tutorial estrategia didáctica: enseñanza dirigida - exploración guiada - libre descubrimiento .

FUNCIÓN: Ejercitar habilidades - instruir - informar - motivar - explorar - entretener experimentar/resolver problemas - crear/expresarse - evaluar.

DOCUMENTACIÓN: - MANUAL DE USUARIO - EN CD Y ONLINE
SERVICIOS ON -LINE: CONSULTAS Y RETROALIMENTACIÓN
REQUISITOS TÉCNICOS:PC

Otros (hardware y software):

Como requerimientos del sistema se puede utilizar con Windows 98/2000/XP, con un procesador Intel ${ }^{\circledR}$ o AMD a 400 mhz o superior con 128 Mbytes de RAM.

Para la instalación de la aplicación no se necesita contar con un gran sistema aunque, eso sí, se debe de tener al menos un equipo dotado del hardware necesario para correr de forma fluida Windows 98 o superior y los componentes multimedia. 


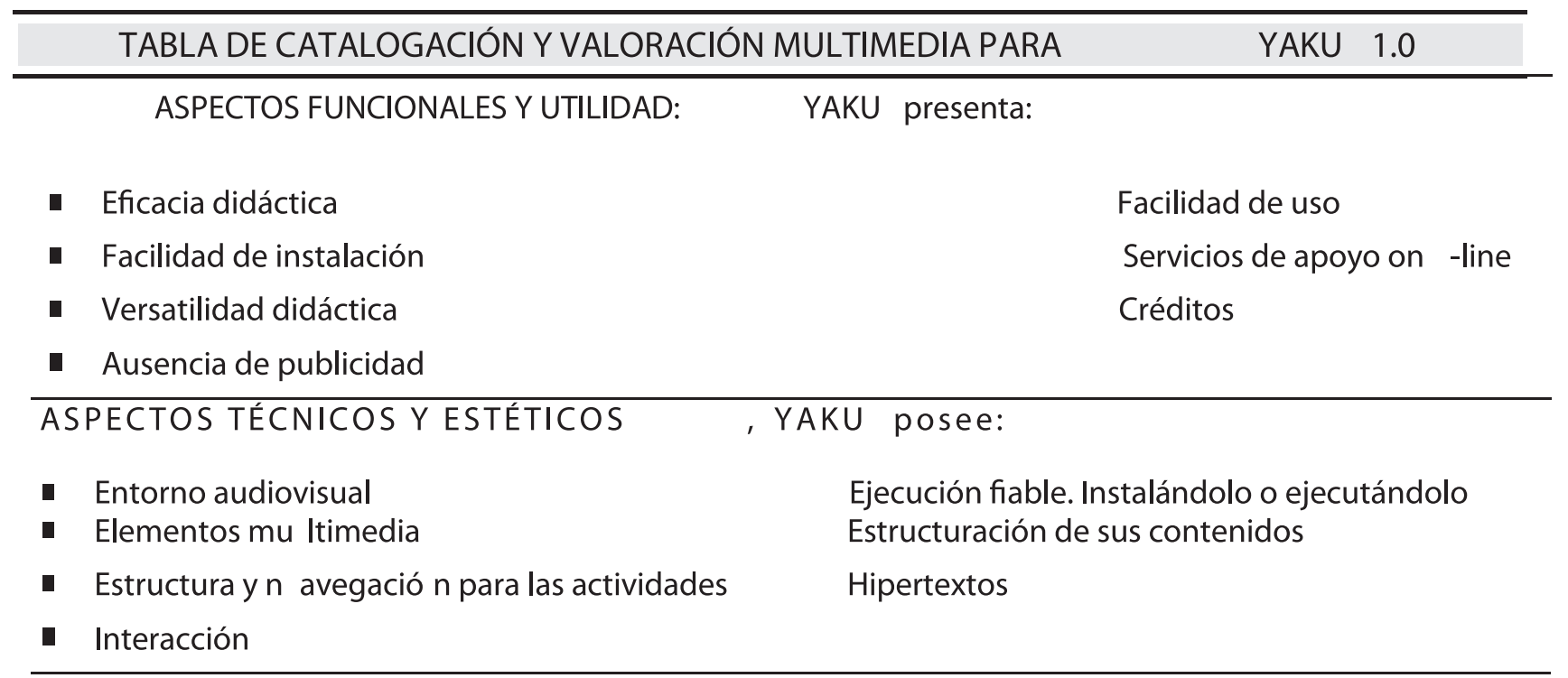

ASPECTOS PEDAGÓG ICOS, YAKU tiene:

- Especificación de los objetivos

Tutorización y evaluación

- Capacidad de motivación Enfoque aplicat ivo/ creativo de las actividades

- Adecuación a los destinatarios Fomento del a utoaprendizaje Recursos para buscar información (palabras clave) Facilita el trabajo cooperativo Potencialidad de los $r$ ecursos didáctico RECURSOS DIDÀCTICOS QUE UTILIZA ， YAKU contiene:

- FOTOGRAFIAS ANIMACIÓN

- GRÁFICOS PREGUNTAS

- IMÁGENES EJERCICIOS DE APLICACIÓN

- SONIDO S ACTIVIDADESDE AUTOEVALUACIÓN

- VÍDEO, FOTOGRAMAS LECTURAS

ESFUERZO COGNITIVO QUE EXIGEN SUS ACTIVIDADES

CONTROL

MEMORI ZACIÓN / EVOCACIÓN

COMPRENSIÓN / INTERPRETACIÓN

COMPARACIÓN/RELACIÓN

ANÁLISIS / SÍNTESIS
PLANIFICAR / ORGANIZAR / EVALUAR

HACER HIPÓTESIS / RESOLVER PROBLEMAS

EXPLORACIÓN /

EXPRESIÓN 


\section{CONCLUSIONES Y RECOMENDACIONES}

Por medio de los resultados de las encuestas se identificó que el tema del agua es fundamental para el desarrollo económico, social y político de cualquier territorio; por lo tanto se deben diseñar e implementar estrategias didácticas para fortalecer los procesos de enseñanza-aprendizaje sobre la temática del agua en las instituciones.

Se logró realizar un material educativo computarizado denominado YAKU versión 1.0, como herramienta didáctica multimedia en formato CD ROM, para poner a disposición de los diferentes usuarios asociados con la gestión integral de los recursos hídricos.

Se logró desarrollar una metodológica propia, dinámica y didáctica teniendo en cuenta el contexto educativo y socio-cultural donde se aplicaron los principales parámetros considerados para el desarrollo de MEC utilizando dos fases: prediseño y condiciones pedagógicas del MEC, y procesamiento y condiciones técnicas del MEC.
Con el diseño y creación del MEC YAKU 1.0 se generó un producto real que valida y evidencia la puesta en marcha de una didáctica innovadora en relación con la integración de la temática del agua, por lo que se sugiere este formato para futuras innovaciones pedagógicas con soporte tecnológico. Posteriormente, se deben abordar los aspectos relacionados con la utilización y el comportamiento del MEC en el contexto educativo.

Fomentar la puesta en práctica en desarrollar MEC en las instituciones educativas ya que presentan múltiples ventajas como herramienta tecnológica en los procesos de enseñanza - aprendizaje y la integración de saberes.

El diseño y creación de MEC presenta la ventaja que el docente es un guía acompañante y la tecnología un recurso didáctico renovador que posibilita la aplicación de la comunicación educativa, el cual se refiere al mejoramiento de la información y comunicación en la educación a través del uso de herramientas infovirtuales y computacionales.

\section{BIBLIOGRAFÍA}

Agua 2003. Conferencia Internacional Usos Múltiples del Agua: para la vida y el desarrollo sostenible. Universidad del Valle/ Instituto CINARA, IWA International Water Association. Cartagena de indias, Colombia.

Alzate, H. F. Bustamante, C. A. Y Monzalve, E. A. 2008. Diseño de un material educativo computarizado (MEC) para la comprensión e interpretación de los componentes del caudal ecológico y la gestión integral del río Quindío. Revista de la Asociación Colombiana de Ciencias Biológicas ACCB. Colombia. 19: 34-41.

Ausubel D., Novak J. Y Hanesian H. 1997. Psicología educativa. Un punto de vista cognitivo. Trillas. Ediciones 1978, Reedición en 1997.

Bautista, g. Borges, f. Y fores, a. 2006. Didáctica universitaria en entornos virtuales de enseñanza - aprendizaje. Nercea S.A de Ediciones. Madrid, España. $246 \mathrm{pp}$.

De la mora sánchez, c. L. 2002. El uso de tecnologías y su aplicación en el campo educativo. En: Revista de educación EDUCAR, tercera época № 21 p. 62

García-duque, c. E. materiales educativos computarizados: parámetros de calidad: Memorias del primer seminario de herramientas para desarrollo de multimedia y software educativo. Armenia. Universidad del Quindío. S. D. p. 11. 30 Ibid. P. 11

Global water partnership (gwp). 2000. Manejo Integrado de los Recursos Hídricos.

http://www.cepis.org.pe/bvsarg/e/fulltext/mirh4/mirh4.pdf

Sánchez, I. D. Y sánchez, a. 2004. Uso eficiente del agua. IRC International Water and Sanitation Centre. CINARA Instituto de Investigación y Desarrollo en Agua Potable, Saneamiento Básico y Conservación del Recurso Hídrico de la Universidad del valle.

Visscher, j.t., bury, p., gould, t. And p. Moriarty. 1999. Integrated water resource management in water and sanitation projects. IRC International Water and Sanitation Centre, Delft, the Netherlands. 